\title{
Guidelines for conducting a pre-post intervention study with preschool children using fMRI: The rationale behind the methodological choices of a research project on reading acquisition
}

\author{
Jérémie Blanchette Sarrasin ${ }^{1,2^{\star}}$, Lorie-Marlène Brault Foisy ${ }^{1,2}$, Alexandra Auclair ${ }^{1,2}$, \\ Martin Riopel ${ }^{1}, \&$ Steve Masson ${ }^{1,2}$
}

\begin{abstract}
In an effort to build bridges between the fields of neuroscience and education, several research projects using neuroimaging focus on the early childhood period. This period of life is indeed crucial for child development, as early educational experiences can have a significant influence on subsequent learning. However, conducting neuroimaging projects with young children presents several challenges, both for participants and researchers. For instance, fMRI technology requires that participants move as little as possible during data acquisition, which can be a real challenge for a young child. Building on previous papers that make recommendations to facilitate the conduct of fMRI research involving young children, the present article proposes to discuss the rationale behind the methodological choices of a particular case: the case of an fMRI intervention study conducted with preschool children. An fMRI intervention study with young children is indeed particularly challenging, especially when it includes two fMRI sessions, pre- and post-intervention. Since no previous articles have focused on the specific challenges encountered in this specific type of study, this article aims to discuss the main questions that may arise regarding different key moments of this type of research project: recruitment of participants, preparation for fMRI sessions, fMRI data acquisition and data analysis.
\end{abstract}

\footnotetext{
${ }^{1}$ Département de didactique, Université du Québec à Montréal, Montréal, QC, Canada

${ }^{2}$ Laboratory for Research in Neuroeducation, Département de didactique, Université du Québec à Montréal, Montréal, QC, Canada

*Author email address: blanchette_sarrasin.jeremie@uqam.ca
}

To cite this article: Blanchette Sarrasin, J., Brault Foisy, L.-M., Auclair, A., Riopel, M., \& Masson, S. (2020). Guidelines for conducting a pre-post intervention study with preschool children using fMRI: The rationale behind the methodological choices of a research project on reading acquisition. Neuroeducation, 6(1), 24-36.

DOI: https://doi.org/10.24046/neuroed.20200601.24

Received on Feb. 22, 2019. Received in revised form on Aug. 22, 2019.

Accepted on Aug. 26, 2019. Available online on June 6, 2020.

Neuroeducation, 6(1), 24-36

ISSN: 1929-1833

All rights reserved (C) 2020 - Association for Research in Neuroeducation 


\section{Introduction}

In the last fifteen years or so, many researchers have focused on the relevance, for the field of education, of a better understanding of brain functioning (Ansari \& Coch, 2006; Goswami, 2006; Sigman, Peña, Goldin, \& Ribeiro, 2014). This has given rise to an emerging research field often referred to as neuroeducation (Ansari, De Smedt, \& Grabner, 2012; Masson, 2012; The Royal Society, 2011). By studying learners' brain activity, neuroeducation can bring an additional level of analysis to some educational issues (Masson \& Borst, 2017). Indeed, neuroimaging data is distinct and complementary to behavioral data such as performance, reaction time or verbal responses, which are most commonly used in education research (Vogel, Matejko, \& Ansari, 2016). The behavioral outcomes of students at a task are most often used as clues for researchers and educators when evaluating the impact of an intervention. However, among other things, brain data could allow to observe effects that are not always detectable through behavioral data alone (Ansari et al., 2012). For instance, two interventions may lead to a similar improvement in participants' performance but show fundamental differences in brain activity (Morgan-Short, Steinhauer, Sanz, \& Ullman, 2012). These differences in neural outcomes provide more information about the nature of the learning taking place. Examining the brain activity is therefore another way to understand how educational settings, such as the type of intervention used, impact learning. Neuroeducation studies can provide a complementary understanding of certain educational phenomena in a more fundamental way (Ansari et al., 2012).

Furthermore, as some specificities of the developing brain can only be observed in children, some neuroeducation researches focus precisely on the study of children's brain activity and structure (Wilke, Holland, Myseros, \& Schmithorst, 2003). There is still much to discover on the development and maturation of functional brain systems (Ansari et al., 2012). However, it is well known that some regions of the brain develop over time, such as those related to executive functions (Supekar \& Menon, 2012). It thus appears necessary to conduct studies with participants of different age groups, including young children (Wilke et al., 2003). Investigating the early childhood period is also essential in order to develop a better understanding of the neural origin of some learning disabilities (Bookheimer, 2000). For instance, differences in brain activity between dyslexic children of different ages have been observed (Shaywitz et al., 2002), which highlights the presence of a developmental component in such disabilities. Moreover, investigating the early childhood period can allow to better understand the neural correlates of early learning, such as reading and numeracy (Brault Foisy, Riopel, \& Mevel, 2017). For example, in order to understand the brain mechanisms at play when learning to read, it appears necessary to study child participants who have not yet learned to read, or who are at the very beginning of this learning process. It also seems important to study the effects of different educational interventions or experiences on brain functioning at this age.
This seems even more important considering that many studies have shown that early educational experiences can have a strong impact on brain development, as well as on later learning, behavior, and health (Shonkoff \& Levitt, 2010; Wade, Fox, Zeanah, \& Nelson, 2019). In this sense, it has been demonstrated that significant adversity experienced during early childhood can lead to long-term negative consequences on such aspects (Shonkoff \& Levitt, 2010). Early educational interventions can partially offset the effects of poverty and inadequate learning environments on child development and achievement, as producing meaningful and lasting effects on cognitive, social and academic outcomes (Barnett, 2011). Studying the effects of different early educational interventions is hence not only scientifically relevant, but also socially relevant since interventions that effectively support brain development could act as a protective factor for underprivileged children and promote equal opportunities for all children. For example, studies have shown that educational interventions using guided play could help promote the development of spatial language (Ferrara et al., 2011) and executive functions (Diamond \& Lee, 2011) in early childhood. Neuroeducation studies focusing on this period of life can therefore help answer some specific questions and provide access to information that would not otherwise be available.

Among all the tools for measuring brain activity, functional magnetic resonance imaging (fMRI) is one of the most commonly used techniques (Larose, Pineau, \& Poirel, 2017). fMRI allows, in a non-invasive and painless way, to measure the brain activity of participants while they perform a cognitive task. The main advantage of this technique is its high spatial resolution, which means that it allows to accurately measure where the activity occurs, even if it is in a region that is located in a deep layer of the brain (Gosseries et al., 2008). Over the years, a significant number of studies using fMRI have been conducted with child participants. Some studies have, for example, investigated the brain regions involved in the development of early mathematics skills (Houdé et al., 2011; Rosenberg-Lee, Barth, \& Menon, 2011) or those involved in emotional self-regulation (Lévesque et al., 2004). Some researchers have also pointed out advantages for children participating in fMRI data collection, such as the opportunity to learn how their brain works and to develop a better understanding of the relationship between the mind and the brain (Rossi et al., 2015).

The use of fMRI is however associated with several constraints, which are mainly related to the specific environment of the fMRI, which is considerably different from a natural classroom context (Masson \& Borst, 2017). Collecting fMRI data with children therefore poses particular challenges for both the child and the researcher (Vogel et al., 2016). For instance, due to the effect of movement on the quality of the images collected, limiting movement as much as possible is one of the main challenges associated with fMRI data collection with young participants (Thomas \& 
Casey, 2000). There are also other challenges related to the steps before and after fMRI data collection, namely the need to establish a strong collaboration with parents, the selection and preparation of the children (e.g., regarding the fear and stress generated by the scan), and the pre-processing of data prior to statistical analysis. These challenges raise a number of questions for the researchers planning the project: How is it possible to limit the movement of children inside the scan? Is there a way to prepare them or to contextualize the scanning session in order to reduce the stress they might feel? What should be the total duration of the scan? Etc. Of course, researchers might intuitively think of ideas or answers to these questions. However, given the necessity of conducting studies with young children using fMRI, these specific challenges and the importance of the children's wellbeing during the whole process, it appears essential to more systematically identify and discuss strategies to facilitate the conduct of this type of data collection.

The present article proposes to present the rationale behind the methodological choices of an fMRI intervention study conducted with preschool children, in order to discuss the main questions that may arise during this type of project. This specific case is particularly interesting as it includes an educational intervention, aiming at teaching reading, and two fMRI data acquisitions, pre- and post-intervention. Although some articles already provide recommendations and guidelines regarding fMRI projects with young children, none specifically focused on the challenges encountered in one that includes an educational pre-post intervention. However, the implementation of an intervention between two neuroimaging data collection times can pose additional challenges, as the child's experience during the first scan has a decisive influence on the rest of the project. Previous articles also mainly focused on challenges related to the moment of data acquisition (e.g., limiting movement) but less on others. The aim of this paper is thus twofold: (1) discuss some recommendations made in previous papers that address the conduct of fMRI studies involving children, and (2) discuss the choices that were made during this project, along with their justifications, regarding aspects beyond data acquisition (e.g., recruitment) and the challenges related to the intervention and pre- and post- fMRI sessions. This paper therefore provides guidelines in order to facilitate the thought process of researchers who would like to conduct a similar research project. Naturally, a complete procedure that can be systematically applied to any research project does not exist, as the choices are necessarily closely linked to the specificities of each research project, such as the age of the children taking part in the project, the available funds, the location and specific procedure of the center where the data collection takes place, the research questions, etc.

This article is divided according to four key moments of the project to which great attention should be paid by the researcher: (1) recruitment of participants, (2) preparation for fMRI sessions, (3) fMRI data acquisition, and (4) data analysis. In the light of both the recommendations provided in previous articles and the experience of this project, Table 1 aims to summarize transferable points to consider during each of these key moments. The next section presents the central objective of the pre-post intervention study discussed in this paper. A discussion of the four key moments follows.

\section{Central objective of the pre-post intervention study}

The central objective of the study discussed in this paper was to verify whether two distinct educational interventions to teaching reading would be associated with different patterns of brain activity in children that didn't know yet how to read (preschoolers, mean age: 5.9 years old). Participants were randomly assigned to two groups, each taking part in a different reading intervention. Each intervention directed the participant's attention to a different level of analysis of the word (grapheme-phoneme level vs. whole-word level). We chose to carry out the interventions individually rather than in groups through a one-to-one teaching relationship in order to ensure that participants were fully focused and active during these sessions. Neuroimaging data was collected before and after the intervention (pretest and posttest) for each of the two groups of participants. As previously mentioned, this study thus presented a double challenge as it simultaneously involved a pre-post intervention study, for which the loss of participants is often greater (Campbell \& Stanley, 1963), and an fMRI study, which poses a number of specific challenges, particularly with young children. It was therefore crucial to ensure that the fMRI session was experienced positively by the participants in order to keep them involved in the process for the subsequent reading interventions and the second fMRI session at the very end of the project. Figure 1 presents the project's sequence of steps. Each of the steps are explained in detail in the next sections.

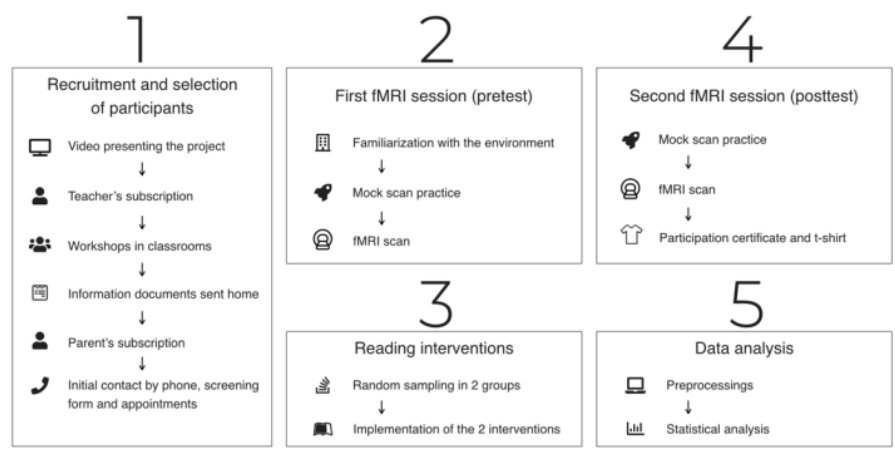

Figure 1. Project's sequence of steps. Components of each of the five main steps of the project are identified.

\section{Participant recruitment and selection}

The first key moment of concern when conducting an intervention fMRI study with young children is the recruitment and selection of participants. The recruitment and selection of children for fMRI sessions can represent a 
considerable challenge, especially when the children are young, as is the case in the study discussed here. Parents and children may indeed initially feel anxious or afraid of the idea of participating in an fMRI session. In fact, researchers agree that one of the main obstacles in developmental neuroimaging is the child's anxiety level (Bookheimer, 2000; Davidson, Thomas, \& Casey, 2003; Kotsoni, Byrd, \& Casey, 2006; Poldrack, Paré-Blagoev, \& Grant, 2002; Raschle et al., 2009). Another challenge in the recruitment phase is that the younger the participants are, the shorter the time of brain image acquisition should be. However, the shorter the time spent to collect the brain data, the larger the number of participants required to ensure the statistical significance of the data collected (Mumford \& Nichols, 2008). More participants are thus needed in this type of study, which highlights the importance of an effective recruitment process. In addition, as with all neuroimaging studies, the researcher must ensure to minimize neural variability between participants. For example, according to some studies (Mazoyer et al., 2014; Narr et al., 2007; Pujol, Deus, Losilla, \& Capdevila, 1999), manual preference can be associated with differences in the functional localization of certain cognitive abilities, such as language. Significant differences in brain structure may also exist between individuals of different ages, especially during early childhood (Durston et al, 2001). Depending on the research questions, these constraints can call for stringent selection criteria and can complicate the recruitment of young participants. Byars et al. (2002) even suggest that, when participants are young children, twice the number of participants needed should be recruited to compensate not only for the exclusion of some participants due to particularities mentioned above, but also for the possible loss of participants throughout the project.
The large number of participants to be recruited is therefore an important challenge.

Although previous articles highlight the importance of recruiting a large number of participants, few discuss how to facilitate the process. This section thus provides indications by presenting how the recruitment of children was conducted in this study. To increase the odds of success, recruitment was first done via preschool teachers. In order to reach a large number of preschool teachers, a diffusion phase was implemented. A video (see Figure $2 \mathrm{~A}$ ) explaining the project's objectives and what students' participation concretely involved was broadcast through official academic channels such as school boards as well as social media (with the approval of the ethical committee), in order to reach as many teachers as possible and to offer the possibility to many preschoolers to take part in the study (the complete video is available in French at https://youtu.be/RSgslA0_dt8). The teachers interested in the project were invited to complete a short registration form and were subsequently contacted to validate their interest. Over 60 preschool teachers registered on the list. A one-hour workshop was then offered to them in their class. The aim of this workshop was to discuss in a playful way with preschoolers about the brain and its functioning using a brain mascot (see Figure 2B). A total of 44 workshops were given, allowing to reach around 800 preschool children. This phase of recruitment shows how teachers can be stakeholders in the conduct of a research project, which is particularly interesting in the case of an educational intervention study including two fMRI sessions. The implementation of an intervention indeed presupposes that the study takes place over a longer period of time and it thus appears helpful to involve the school in the process.
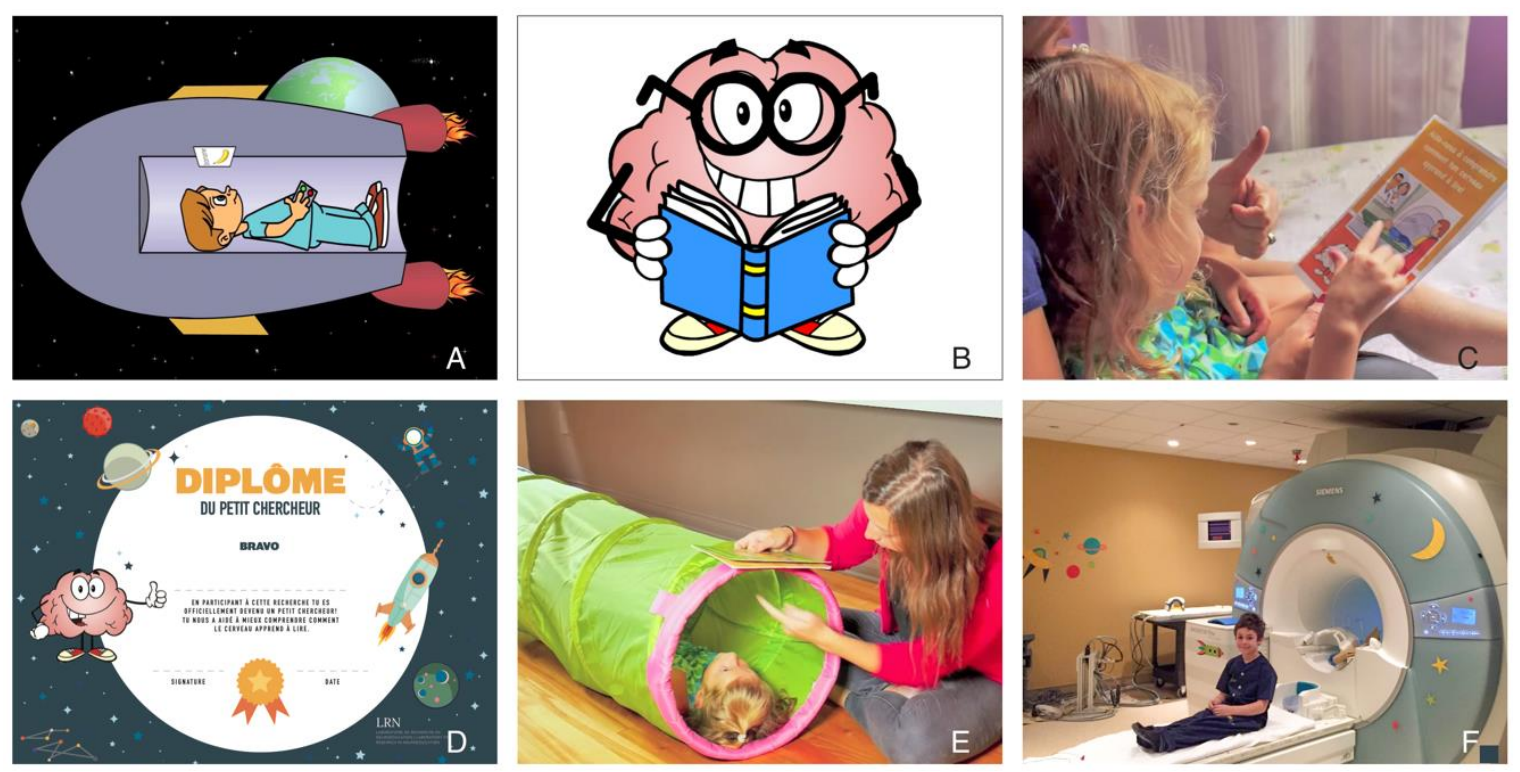

Figure 2. Various images of the project. A. An image captured from the project presentation video that represents the analogy of space travel. B. The brain mascot that served as the main visual referent throughout the project. C. A young girl reading the booklet intended for the children with a parent. D. The participation certificate that was given to each child at the end of the project. E. The same young girl practicing staying still in a tissue tunnel with the help of a researcher. F. A young boy who is about to take part in the fMRI scan. 
The second phase of recruitment consisted in sending home information documents about the project for all children that took part in the workshop. The documents consisted in 1- a booklet intended for the child (see Figure 2C), 2- a leaflet for the parents, and 3- a reply form, all displaying the brain mascot as a familiar visual reference for the child when consulting them at home. Parents and children interested in participating in the project returned the reply form to the child's teacher, who compiled the information in a secure online form. In total, 116 parents showed interest in having their child participate. Based on the availability of the MRI machine, four cohorts of preschoolers were created, spaced at one-week intervals. Initial contact was then made with parents by phone to explain how the project would proceed and to answer any questions they may have. A screening form was also completed with them by phone to ensure that their child did not have a medical restriction to participate in a neuroimaging session. If the child had no restrictions and met the selection criteria (in this case, being a right-handed preschool student, not being able to read, and not having been diagnosed with a disability or disorder), both appointments (pre and post) for the imaging sessions were scheduled during that phone conversation. Of the 116 parents initially interested in their child's participation, 48 children were selected to participate in the project. Several children could not be selected for different reasons: left-handedness, disability or disorder (dyspraxia, ADHD, intellectual disability, etc.), medical condition preventing participation in an fMRI session, too much fear for the child to participate, academic delay (e.g., the child entered school 1 or 2 years late), etc. Some of the parents also decided that they no longer wanted their child to participate in the project. The main reason given was the lack of time to accompany their child during the neuroimaging sessions (even though some time slots were available during the evening). In many cases, it was also not possible to reach the parents by phone. The first box in Figure 1 presents a summary of the steps associated with the recruitment and selection of participants. For each scan session, a monetary compensation of $\$ 20$ was offered for participation in the project, as well as a sum of $\$ 20$ to offset the costs associated with travel to the neuroimaging center. At the very end of the project, each child also received an image of their brain as thanks for their involvement, as well as a participation certificate (see Figure 2D) and a t-shirt bearing the image of the brain mascot.

In sum, the recruitment phase appears particularly important in the context of a project involving an educational intervention, and even more so when it also includes a prepost fMRI data collection. The multiplicity of steps over time is indeed likely to lead to a greater loss of participants. Establishing a strong collaboration with parents and teachers from the start, as it was done in this project, seems to be an effective and meaningful approach. It also seems important to share the main results obtained with the schools, parents and children, for example through information sessions or conferences, in order to inform them, value their participation and perpetuate collaborative work. Table 1 presents a summary of key points to consider.

\section{Preparation for fMRI sessions}

The second key moment to consider is the preparation for fMRI sessions. In fact, as mentioned in the introduction, the challenge of a pre-post intervention study that uses fMRI is that the child must not only succeed in completing the first scan, but the experience must be pleasant enough to repeat a second time after the intervention has taken place. Intervention studies already generally suffer from experimental mortality (Campbell \& Stanley, 1963), but the risk is even greater when using fMRI, because if the child (and/or parent) perceives the first experience as stressful, the child might not be inclined to repeat it. Preparation of participants before data collection is therefore crucial (Wilke et al., 2003), although it can be time-consuming (Larose et al., 2017). In order to maximize data collection and to limit associated constraints, but above all to ensure that the child has a pleasant experience participating in the study, the researcher must prepare the child psychologically and physically for the fMRI session (Raschle et al., 2009). Preparation can require more than one meeting to introduce the project to the children, inform them about how the fMRI scan works, familiarize them with the environment in which the images will be taken, introduce them to the cognitive tasks, explain the steps of data collection and allow them to practice to stay as still as possible (Bookheimer, 2000; Vogel et al., 2016; Wilke et al., 2003). Indeed, in their meta-analysis aiming to identify the best ways to prepare a child for an fMRI data collection, Leroux, Lubin, Houdé, and Lanoë (2013) showed that carrying out a full preparation before the fMRI session increases the success rate of data collection in addition to reducing data exclusion due to a high movement rate. A rigorous preparation was thus carried out during the present research project to ensure that the child would enjoy the experience. We concretely describe it here by directly addressing the two moments of preparation: (1) at school and (2) at the neuroimaging center.

\subsection{Preparation conducted at school}

The children participating in this study were prepared for the fMRI sessions via the workshop in their classrooms. The workshops were thus not only part of the recruitment process, but they also played a role in preparing the children for the fMRI sessions. The preparation that took place during these workshops consisted in different games and activities explaining to preschoolers the utility, functions and functioning of their brain. Throughout the process, the brain mascot was used to present this information in a ludic way. Indeed, Raschle et al. (2009) suggest using child-friendly themes so that the children have a greater desire to engage in the process. The functioning of an fMRI session was also explained and imagined like space travel; the scan being the spaceship, and the child an astronaut with a mission to accomplish (see the different images in Figure 2). Children were invited to simulate the travel of an astronaut in space by entering in a tissue tunnel representing simultaneously the spaceship and the scan (see Figure 2E). Children were also invited to try out a homemade fMRI antenna, representing 
the helmet the astronaut has to wear to go to space and the real scan antenna, to get used to the feeling. In the tunnel, their mission consisted in answering questions similar to those that would be asked in the real scan, using a mock response pad while being as still as possible. To explain the impact of movement on the quality of the images, the analogy of a digital camera was given, explaining that the scan was also taking pictures, and thus that movement in the scan would produce blurry pictures. This initial training, inspired by Houdé et al. (2011), allowed preschoolers to understand and become more familiar with the general procedure of a neuroimaging session, in a context (their classroom) in which they felt comfortable and surrounded by trusted persons.

\subsection{Preparation conducted at the neuroimaging center}

In this project, a second step of preparation was also performed directly at the research institute prior to each of the fMRI sessions, in order to offer another opportunity for the child to practice. As Vogel et al. (2016) suggested, familiarization with the scanning environment and associated tasks are beneficial for a successful execution of the sessions. Therefore, on participants' arrival, a member of the team welcomed the child and his parent, wearing a t-shirt of the brain mascot to provide a familiar landmark. After revising the screening form with the parent, and obtaining the consent form signed by the parent and child (the child could write his name if he was able to, or symbolically color a smiley face), a little snack was offered to the child while being shown around the site. In order for the child to feel comfortable and confident, many elements of the environment of the research institute were adapted, as suggested by Houdé et al. (2011), without having to defray high costs. For instance, playful images with the effigy of the brain mascot and recalling space travel were displayed on the premises of the research institute. These images illustrated the main steps to be taken and rooms (1- simulation room, 2- fMRI room). The person in charge of the data collection was to take the child on a brief tour of the place, showing him the images, and explaining what was going to be done, and in what order. He could also answer the child's questions and make him feel secure.

Several researchers (Barnea-Goraly et al., 2014; de Bie et al., 2010; Leroux et al., 2013; Raschle et al., 2009) also point out that a good strategy to reduce the child's stress and anxiety while reducing movement during data collection consists in carrying out training with a mock scan (i.e., a reproduction of the fMRI scan without electromagnetic field emission) directly at the neuroimaging center. Indeed, because of the size of the scan, its loud noise and narrow bore, practicing in a mock scan allows the child to become familiar with the fMRI environment (de Bie et al., 2010). In addition, because the children are not able to look at the response pad during the scan, training in a mock scan is a strategy to help them practice answering with the response pad (Larose et al., 2017).

In the present study, the child was invited to the simulation room to "practice his mission in space" in a mock scan. The first step consisted in explaining to the child the instructions of the tasks he would have to perform in the real scan using the response pad. Before entering the mock scan, a first practice was done in front of a computer screen. The child was asked to answer about ten questions similar to those used in the tasks, with the response pad. A second practice then took place inside the mock scan. Feedback was given to the child following his practice to let him know if he had accomplished his mission well by performing the tasks and by remaining as still as possible. This step also allowed to screen the children for claustrophobia. The training part inside the mock scan seemed particularly important with participants of this age, as it allowed them to understand in a very concrete way what the real scan session would be like. Also, as suggested by de Bie et al. (2010), the sounds emitted by the real scan were also presented to the child (comparing them to familiar sounds, like a train or a ship) so that he would not be surprised and would understand that they were normal. For some children who were more fearful, parents' collaboration was facilitating, as they could accompany their child during the training in the mock scan room. Finally, we also paid attention to the vocabulary used during the entire project, taking care to avoid words with negative connotations. For example, we would ask a child if he felt comfortable instead of if he was scared, in order not to induce stress or fear.

All of these considerations (see Table 1 for a synthesis) seem truly important in the preparation of the child for fMRI sessions to ensure that he appreciates the experience, especially since intervention studies usually imply several data collection times.

\section{5. fMRI data acquisition}

The third key moment is data acquisition itself. One of the major concerns in fMRI data acquisition with young children is motion control, which is crucial to ensure image quality. During the fMRI scan, participants should indeed move as little as possible to prevent images from containing motionrelated artifacts (Byars et al., 2002). This implies that the child must maintain control over himself for several minutes, which can be more difficult than for an adult participant (Bookheimer, 2000). Indeed, it is expected with children that a large proportion of data will be lost due to excessive motion (Poldrack, Mumford, \& Nichols, 2011). Even though there appears to be a consensus that conducting a mock scan practice greatly improves the likelihood of a successful scan (Leroux et al., 2013), it still seems necessary to plan the data acquisition sequence in such a way as to reduce possible movement. Therefore, when planning the neuroimaging acquisition sequence per se, several questions may emerge. For example, at what point in time should the anatomical images be acquired? How to best maintain the child's attention and interest? In which order should the tasks be performed (if there are several of them)? What is the most appropriate duration of the tasks? Are there acquisition parameters that are better suited for young participants (especially due to the larger possibility of movement)? 
In the present study, when neuroimaging acquisition was conducted (see Figure 1 for the sequence of steps), we first made sure that installation time with the child was sufficient. With the help of a technician (also wearing a t-shirt bearing the image of the brain mascot) and the person in charge of data acquisition, the participant was then positioned on the scanning table (see Figure $2 \mathrm{~F}$ showing a picture of a young boy who is about to take part in the fMRI scan). To minimize the risk of movement during image acquisition, the technician ensured that the participant's head was well positioned, and cushions were placed on each side. In order to obtain the cleanest anatomical images and because children are likely to move more as the session progresses, we chose to collect these images at the beginning of every session. Performing the anatomical scan at the beginning also made it possible to use the functional data collected, even if the participant did not complete the entire session. Since the anatomical images are indeed necessary to perform $\mathrm{CO}^{-}$ registration during the preprocessing steps, choosing to conduct the anatomical scan at the end of the session could lead to the loss of the collected functional data if the participant would not complete the entire MRI session. On the advice of the neuroimaging center staff, we also decided to conduct a T1-weighted multi-echo MPRAGE (MEMPRAGE) (van der Kouwe, Benner, Salat, \& Fischl, 2008) because it allowed us to reduce the duration of anatomical acquisition to about 6 minutes (instead of a more standard MPRAGE session of 9-10 minutes) while preserving similar image quality. Another technique used to limit movement during anatomical acquisition was to present the participant a short and calm animation movie in which a character makes a journey into space, so the child would be sufficiently attentive and move as little as possible (Houdé et al., 2011). The theme of the movie also aimed to place the child in a reassuring context from the start of the scanning session.

Vogel et al. (2016) recommend using short protocols with children due to their limited attention and immobility capacities. Consequently, during functional image acquisition, the first task was designed to be as short as possible: it took about 12 minutes in total and was subdivided into four equivalent series of three minutes, each presenting a limited number of stimuli. This task was intended to observe the brain activity generated during the reading of words. In order to do so, participants performed a reading-verification task in which they had to evaluate if a word matched an image. They gave their answer (yes or no) by pressing one of the two buttons of a response pad. Considering the young age of the participants, it was also necessary to make the response process as easy as possible. Very often, the response pads used in neuroimaging data collection with adults have four buttons (because the tasks involve several possible answers). However, in this case, the task involved a simple choice between two answers. It was thus important to develop a strategy to ensure that the child was not mistaken about which buttons to press. To minimize the risk of response error, we decided to use a child-friendly response pad with only two buttons. Using specific response tools that are adapted in size and shape to the age of the participant has indeed proven helpful (Kotsoni et al., 2006). Another strategy could have been to add textures on the buttons in order to provide a tactile landmark for the child in case he no longer remembered which one to press. During the installation of the participant in the fMRI device, we also made sure that the response pad was carefully positioned so that the child felt comfortable when answering and did not wiggle in the scan to reach the pad (Raschle et al., 2009).

Because one of the tasks required a higher level of cognitive engagement from the child (reading the words and evaluating the accuracy of the matching), we chose to have the child complete it first. The second task was also designed to be as short as possible. It was divided into two equivalent series and took about seven minutes in total. This task aimed to assess the functional organization of the visual ventral pathway (inspired by Monzalvo et al., 2012). It was a more passive task because participants simply had to look at different categories of objects appearing on the screen and press a button on the response pad when a target (the brain mascot image) was displayed. The instruction given to the participant to press the button when the mascot appeared was intended solely to ensure that they remained attentive and that they were looking closely at the stimuli presented on the screen.

In addition to the recommendation to use short protocols, Vogel et al. (2016) also suggest segmenting the tasks to allow the child to take breaks. Therefore, between each series of tasks, a break of one to two minutes was taken so that the participant could benefit from a small rest period. During these breaks, the experimenter could interact with the participant by speaking to him via microphone to make sure that he felt good and that he was relaxed enough. The child was also reminded of the instructions, the remaining steps, and to move as little as possible, and was given positive reinforcement in order to keep him motivated. At the end of this fMRI session, the person in charge of data collection also asked the child if he enjoyed his experience and reminded him that he would come again for a second scan (the posttest), in order to prepare him mentally. After the first fMRI session, all participants were involved in a five-week intervention that aimed to teach them to read 20 words (see Figure 1, step 3). To ensure that the child continued to feel comfortable during the process, these interventions were carried out in their school environment. Indeed, the experience of the first fMRI session is likely to affect the child's willingness to participate in the interventions and the second fMRI session, as the experience of the interventions may affect his desire to come back for the second scan. The post-intervention fMRI session was conducted in all respects like the first. All steps of the project, from recruitment to the end of data collection, took place from September to April.

\section{Data analysis}

There are other challenges beyond data collection for researchers conducting fMRI studies with young children. The fourth key moment is data analysis. Indeed, before moving forward with analysis, data must be preprocessed to 
control for quality. Data preprocessing involves different steps, of which two in particular could require special consideration due to the young age of participants. The first step, which may require more attention, concerns motion correction (Brault Foisy et al., 2017). This preprocessing step aims to correct differences in the positioning of the head throughout the neuroimaging session, so that a brain region remains at the same position in the standard coordinate system [x y z] for all volumes collected. The overall goal of motion correction is to maximize sensitivity to true activations while minimizing false activations related to motion (Johnstone et al., 2006). The most common motion correction consists of realigning the images by translation and rotation on the 3 axes $\mathrm{x}, \mathrm{y}$ and $\mathrm{z}$ (six parameters rigid body transformation) in order so that they correspond as well as possible to a reference volume (Friston et al., 1996; Poldrack et al., 2011). However, considering that children may be inclined to move more than adults in the scanner during data acquisition, some researchers suggest that an additional correction should be made for residual motion (Brown et al., 2010; Johnstone et al., 2006; Monzalvo et al., 2012). One possible strategy to perform this type of correction is to use a software designed specially to improve fMRI analysis, such as ArtRepair (Mazaika, Hoeft, Glover, \& Reiss, 2009), which has special motion adjustment algorithms. With this type of software, it becomes possible to correct each of the brain volumes for which movement induced an artifact by removing them or interpolating from neighboring volumes (see an example in Monzalvo et al., 2012). This software also allows statistical results obtained before and after the correction of artifact volumes to be compared. Another strategy to realize supplementary motion correction is to add motion regressors in the design matrix (for more details, see Johnstone et al., 2006). It can therefore be appropriate to consider performing movement correction when analyzing fMRI data of young children.

The second data preprocessing step that may require additional consideration is the spatial normalization step. Spatial normalization is necessary in studies that generalize across individuals by carrying out group analyses. Since individual brains are highly variable in their size and shape (Huettel, Song, \& McCarthy, 2008; Poldrack et al., 2011; Rademacher et al., 2001), participants' brains need to be transformed into a common space so that they are aligned with one another (Uylings et al., 2005). To do so, a brain template is used as a target to which all individual images of participants can be aligned (Poldrack et al., 2011).
The templates used to normalize images of adult brains are not necessarily adapted to children's brains (Brault Foisy et al., 2017; Thomas \& Casey, 2000; Wilke, Schmithorst, \& Holland, 2002). Indeed, depending on their age, there are sometimes considerable anatomical differences between the brains of children and adults (Caviness et al., 1996; Fonov et al., 2011; Sanchez, Richards, \& Almli, 2012), which may require the use of a specific brain template for the normalization step. For instance, since the frontal lobe matures late in development (Gogtay et al., 2004), the proportion of the brain occupied by this region differs in childhood and adulthood, thus calling for the use of a specific brain template. Moreover, due to rapid brain growth in the early years of life, significant differences can also be observed in children of different age groups, including brain size, shape and tissue composition (Prastawa, Gilmore, Lin, \& Gerig, 2005; Wilke et al., 2002). Some researchers therefore argue that using an adult anatomical template to normalize data from children may cause significant bias due to developmental differences between adult and child populations (Altaye, Holland, Wilke, \& Gaser, 2008; Machilsen et al., 2007; Wilke et al., 2002, 2003). A possible strategy consists in using a paediatric template in order to realize the normalization when the participants are children (Wilke et al., 2002). Different templates (Fonov et al., 2011; Sanchez et al., 2012) and software, such as Template-O-Matic (Wilke, Holland, Altaye, \& Gaser, 2008) or DARTEL (Ashburner, 2007) can be used via Statistical Parametric Mapping (SPM) to create age-specific brain templates. In summary, in order to obtain clean data, it is essential to consider these elements when planning the analysis (See Table 1 for an overview).

In this project, as the objective was to compare two pedagogical interventions, each intervention acted as a control measure for the other. We also made sure that the two groups had an equivalent starting level at pretest (participants of both groups were non-readers). Reading performance was measured in addition to brain data, to evaluate the difference in performance between the posttest and pretest for each type of intervention. Brain data was analyzed to identify the brain regions that were more activated for each type of intervention (graphemephoneme $>$ whole-word, and vice versa) and those that were more activated after the intervention (posttest) compared to before (pretest), for each intervention. Region-ofinterest (ROI) analyses were also performed with respect to our assumptions about specific regions of the reading network. 
Table 1. Main points to be considered during four key moments of a pre-post intervention study using fMRI with young children

Key moments Main points to consider

Recruitment and selection of participants

Preparation for fMRI sessions

fMRI data acquisition

Data analysis
- Recruit about twice the number of participants needed.

- Involve the school community, teachers and parents in the process (e.g., going into classrooms) and establish a strong collaboration with them.

- $\quad$ Present and diffuse the project in such a way as to reach both adults and children (e.g., video).

- Establish child-friendly visual reference points at the beginning of the process that will be reused throughout the project.

- Design materials specifically for the child (information sheet, consent sheet, participation certificate) to make them feel involved in the process.

- Create a warm atmosphere through interactions with the child.

- Introduce the child to the environment of the scan (visit of the neuroimaging center, presentation of the tasks and steps of the project).

- Plan several training sessions (practicing the tasks, staying still, answering without seeing the response pad, etc.), including a session outside of the neuroimaging center (e.g., classroom).

- Have the child listen to the noise of the scan before the real session.

- Perform a simulation in a mock scan.

- Ensure that the child is in an appropriate condition before the beginning of the scan (not hungry or in need to go to the bathroom, etc.).

- Take the time to install the child in order for him to feel comfortable and secure.

- Ensure that the equipment used is appropriate for the child's age (e.g., response pad).

- Collect the anatomical images at the beginning of the fMRI session.

- Choose shorter acquisition sequences when possible (e.g., MEMPRAGE sequence).

- Plan short tasks for the child to complete in the scan.

- If there are several tasks, plan the most cognitively demanding task first.

- Include breaks during the fMRI session.

- Communicate with the child during the breaks (making him feel secure, reminding him to stay as still as possible, informing him of the remaining steps, etc.)

- $\quad$ Realize supplementary motion correction if necessary.

- Choose brain templates that are appropriate for children's brains for the normalization step. 


\section{Conclusion}

The aim of this paper was to discuss the rationale behind methodological choices in the case of an fMRI pre-post intervention study conducted with preschool children. Since no previous articles focus specifically on challenges encountered in fMRI studies including an educational intervention, this paper provides an interesting perspective as well as supplemental recommendations to facilitate the conduct of fMRI research involving young children. We highlighted anchor points that could be transferable to other research projects using a similar protocol, but with different research questions. By providing useful information to researchers aiming to conduct similar research, this article could facilitate the conduct of future neuroimaging studies with young children. As early childhood is a crucial period in child development, it seems relevant to facilitate such projects while maximizing the well-being of the young children who participate in them. Conducting neuroimaging intervention studies from an early age can allow a better understanding of how different educational interventions lead to different neural correlates. It can thus help to better understand the foundations of different types of learning, and ultimately foster teaching practices that are more naturally compatible with brain development and functioning.

\section{Acknowledgements}

We would first like to thank all the preschool children, parents and teachers whose great interest and generous contribution in time and energy made this project possible. We find them truly admirable. Many thanks also to the staff at the Functional Neuroimaging Unit of the Centre de recherche de l'Institut universitaire de gériatrie de Montréal (CRIUGM), and to all the persons who contributed to this project on any level (i.e., presentation video, recruitment and preparation of the participants, implementation of interventions, data collection and analysis). We would like to address a special thank you to Antony, Lily-Rose and Paul-Émile, who, each in their own way, allowed us to improve this project to ensure the well-being of participating children. The research project was made possible with the support of the Social Sciences and Humanities Research Council of Canada (SSHRC; grant number 435-2015-1791).

\section{References}

Altaye, M., Holland, S. K., Wilke, M., \& Gaser, C. (2008). Infant brain probability templates for MRI segmentation and normalization. Neuroimage, 43(4), 721-730.

https://doi.org/10.1016/j.neuroimage.2008.07.060

Ansari, D., \& Coch, D. (2006). Bridges over troubled waters: Education and cognitive neuroscience. Trends in Cognitive Sciences, 10(4), 146-151.

https://doi.org/10.1016/j.tics.2006.02.007
Ansari, D., De Smedt, B., \& Grabner, R. H. (2012). Neuroeducation - A critical overview of an emerging field. Neuroethics, 5(2), 105-117. https://doi.org/10.1007/s12152-011-9119-3

Ashburner, J. (2007). A fast diffeomorphic image registration algorithm. NeuroImage, 38(1), 95-113. https://doi.org/10.1016/j.neuroimage.2007.07.007

Barnea-Goraly, N., Weinzimer, S. A., Ruedy, K. J., Mauras, N., Beck, R. W., Marzelli, M. J., ..., \& Tsalikian, E. (2014). High success rates of sedation-free brain MRI scanning in young children using simple subject preparation protocols with and without a commercial mock scannerthe Diabetes Research in Children Network (DirecNet) experience. Pediatric Radiology, 44(2), 181-186.

https://doi.org/10.1007/s00247-013-2798-7

Barnett, W. S. (2011). Effectiveness of early educational intervention. Science, 333(6045), 975-978. https://doi.org/10.1126/science.1204534

Bookheimer, S. Y. (2000). Methodological issues in pediatric neuroimaging. Mental Retardation and Developmental Disabilities Research Reviews, 6(3), 161-165.

https://doi.org/10.1002/1098-2779(2000)6:3\%3C161::aidmrdd2\%3E3.0.co;2-w

Brault Foisy, L.-M., Riopel, M., \& Mevel, K. (2017). L'utilisation de l'imagerie par résonance magnétique fonctionnelle : les prétraitements et l'analyse des données. In S. Masson, \& G. Borst (Eds.), Méthodes de recherche en neuroéducation (pp. 61-132). Québec, QC: Presses de l'Université du Québec. https://doi.org/10.2307/j.ctvggx359.9

Brown, T. T., Kuperman, J. M., Erhart, M., White, N. S., Roddey, J. C., Shankaranarayanan, A., ..., \& Dale, A. M. (2010). Prospective motion correction of high-resolution magnetic resonance imaging data in children. Neuroimage, 53(1), 139-145. https://doi.org/10.1016/j.neuroimage.2010.06.017

Byars, A. W., Holland, S. K., Strawsburg, R. H., Bommer, W., Dunn, R. S., Schmithorst, V. J., \& Plante, E. (2002). Practical aspects of conducting large-scale functional magnetic resonance imaging studies in children. Journal of Child Neurology, 17(12), 885-889. https://doi.org/10.1177/08830738020170122201

Campbell, D. T., \& Stanley, J. C. (1963). Experimental and quasi-experimental designs for research. In N. L. Gage (Ed.), Handbook of research on teaching (pp. 171-246). Chicago, IL: Rand McNally \& Co.

Caviness, V. S., Kennedy, D. N., Richelme, C., Rademacher, J., \& Filipek, P. A. (1996). The human brain age 7-11 years: A volumetric analysis based on magnetic resonance images. Cerebral Cortex, 6(5), 726-736. https://doi.org/10.1093/cercor/6.5.726 
Davidson, M. C., Thomas, K. M., \& Casey, B. J. (2003). Imaging the developing brain with fMRI. Developmental Disabilities Research Reviews, 9(3), 161-167. https://doi.org/10.1002/mrdd.10076

de Bie, H. M. A., Boersma, M., Wattjes, M. P., Adriaanse, S., Vermeulen, R. J., Oostrom, K. J., ..., \& Delemarre-Van de Waal, H. A. (2010). Preparing children with a mock scanner training protocol results in high quality structural and functional MRI scans. European Journal of Pediatrics, 169(9), 1079-1085.

https://doi.org/10.1007/s00431-010-1181-z

Diamond, A., \& Lee, K. (2011). Interventions shown to aid executive function development in children 4 to 12 years old. Science, 333(6045), 959-964.

https://doi.org/10.1126/science.1204529

Durston, S., Pol, H. E. H., Casey, B. J., Giedd, J. N., Buitelaar, J. K., \& Van Engeland, H. (2001). Anatomical MRI of the developing human brain: What have we learned? Journal of the American Academy of Child $\varepsilon$ Adolescent Psychiatry, 40(9), 1012-1020.

https://doi.org/10.1097/00004583-200109000-00009

Ferrara, K., Hirsh-Pasek, K., Newcombe, N. S., Golinkoff, R. M., \& Lam, W. S. (2011). Block talk: Spatial language during block play. Mind, Brain, and Education, 5(3), 143-151. https://doi.org/10.1111/j.1751-228x.2011.01122.x

Fonov, V., Evans, A. C., Botteron, K., Almli, C. R., McKinstry, R. C., \& Collins, D. L. (2011). Unbiased average ageappropriate atlases for pediatric studies. NeuroImage, 54(1), 313-327.

https://doi.org/10.1016/j.neuroimage.2010.07.033

Friston, K. J., Williams, S., Howard, R., Frackowiak, R. S. J., \& Turner, R. (1996). Movement related effects in fMRl timeseries. Magnetic Resonance in Medicine, 35(3), 346-355. https://doi.org/10.1002/mrm.1910350312

Gogtay, N., Giedd, J. N., Lusk, L., Hayashi, K. M., Greenstein, D., Vaituzis, A. C., ..., \& Thompson, P. M. (2004). Dynamic mapping of human cortical development during childhood through early adulthood. Proceedings of the National Academy of Sciences, 101(21), 8174-8179. https://doi.org/10.1073/pnas.0402680101

Gosseries, O., Demertzi, A., Noirhomme, Q., Tshibanda, J., Boly, M., de Beeck, M. O., ..., \& De Tiège, X. (2008). Que mesure la neuro-imagerie fonctionnelle: IRMf, TEP \& MEG? Revue Médicale de Liège, 63(5-6), 231-237.

http://hdl.handle.net/2268/31382

Goswami, U. (2006). Neuroscience and education: From research to practice? Nature Reviews Neuroscience, 7(5), 406-413. https://doi.org/10.1038/nrn1907
Houdé, O., Pineau, A., Leroux, G., Poirel, N., Perchey, G., Lanoë, C., ..., \& Mazoyer, B. (2011). Functional magnetic resonance imaging study of Piaget's conservation-ofnumber task in preschool and school-age children: A neoPiagetian approach. Journal of Experimental Child Psychology, 110(3), 332-346.

https://doi.org/10.1016/j.jecp.2011.04.008

Huettel, S. A., Song, A. W., \& McCarthy, G. (2008). Functional magnetic resonance imaging. Sunderland, MA: Sinauer Associates.

Johnstone, T., Ores Walsh, K. S., Greischar, L. L., Alexander, A. L., Fox, A. S., Davidson, R. J., \& Oakes, T. R. (2006). Motion correction and the use of motion covariates in multiplesubject fMRI analysis. Human Brain Mapping, 27(10), 779788. https://doi.org/10.1002/hbm.20219

Kotsoni, E., Byrd, D., \& Casey, B. J. (2006). Special considerations for functional magnetic resonance imaging of pediatric populations. Journal of Magnetic Resonance Imaging, 23(6), 877-886.

https://doi.org/10.1002/jmri.20578

Larose, M., Pineau, A., \& Poirel, N. (2017). L'utilisation de l'imagerie par résonance magnétique: la collecte des données. In S. Masson \& G. Borst (Eds.), Méthodes de recherche en neuroéducation (pp. 39-60). Québec, QC : Presses de l'Université du Québec. https://doi.org/10.2307/j.ctvggx359.8

Leroux, G., Lubin, A., Houdé, O., \& Lanoë, C. (2013). How to best train children and adolescents for fMRI? Metaanalysis of the training methods in developmental neuroimaging. Neuroeducation, 2(1), 44-70. https://doi.org/10.24046/neuroed.20130201.44

Lévesque, J., Joanette, Y., Mensour, B., Beaudoin, G., Leroux, J.-M., Bourgouin, P., \& Beauregard, M. (2004). Neural basis of emotional self-regulation in childhood. Neuroscience, 129(2), 361-369.

https://doi.org/10.1016/j.neuroscience.2004.07.032

Machilsen, B., d'Agostino, E., Maes, F., Vandermeulen, D., Hahn, H. K., Lagae, L., \& Stiers, P. (2007). Linear normalization of MR brain images in pediatric patients with periventricular leukomalacia. NeuroImage, 35(2), 686-697. https://doi.org/10.1016/j.neuroimage.2006.12.037

Masson, S. (2012). Neuroeducation: Understanding the brain to improve teaching. Neuroeducation, 1(1), 1-2. https://doi.org/10.24046/neuroed.20120101.1

Masson, S., \& Borst, G. (2017). Les premières étapes d'une recherche en neuroéducation. In S. Masson \& G. Borst (Eds.), Méthodes de recherche en neuroéducation (pp. 7-38). Québec, QC: Presses de l'Université du Québec. https://doi.org/10.2307/j.ctvggx359.7 
Mazaika, P. K., Hoeft, F., Glover, G. H., \& Reiss, A. L. (2009). Methods and software for fMRI analysis of clinical subjects. NeuroImage, 47(Suppl. 1), S58.

https://doi.org/10.1016/s1053-8119(09)70238-1

Mazoyer, B., Zago, L., Jobard, G., Crivello, F., Joliot, M., Perchey, G., ..., \& Tzourio-Mazoyer, N. (2014). Gaussian mixture modeling of hemispheric lateralization for language in a large sample of healthy individuals balanced for handedness. PLoS ONE, 9(6).

https://doi.org/10.1371/journal.pone.0101165

Monzalvo, K., Fluss, J., Billard, C., Dehaene, S., \& DehaeneLambertz, G. (2012). Cortical networks for vision and language in dyslexic and normal children of variable socio-economic status. Neuroimage, 61(1), 258-274. https://doi.org/10.1016/j.neuroimage.2012.02.035

Morgan-Short, K., Steinhauer, K., Sanz, C., \& Ullman, M. T. (2012). Explicit and implicit second language training differentially affect the achievement of native-like brain activation patterns. Journal of Cognitive Neuroscience, 24(4), 933-947. https://doi.org/10.1162/jocn_a_00119

Mumford, J. A., \& Nichols, T. E. (2008). Power calculation for group fMRI studies accounting for arbitrary design and temporal autocorrelation. NeuroImage, 39(1), 261-268. https://doi.org/10.1016/j.neuroimage.2007.07.061

Narr, K. L., Bilder, R. M., Luders, E., Thompson, P. M., Woods, R. P., Robinson, D., ..., \& Toga, A. W. (2007). Asymmetries of cortical shape: Effects of handedness, sex and schizophrenia. NeuroImage, 34(3), 939-948.

https://doi.org/10.1016/j.neuroimage.2006.08.052

Poldrack, R. A., Mumford, J. A., \& Nichols, T. E. (2011). Handbook of functional MRI data analysis. New York, NY: Cambridge University Press. https://doi.org/10.1017/cbo9780511895029

Poldrack, R. A., Paré-Blagoev, E. J., \& Grant, P. E. (2002). Pediatric functional magnetic resonance imaging: Progress and challenges. Topics in Magnetic Resonance Imaging, 13(1), 61-70. https://doi.org/10.1097/00002142200202000-00005

Prastawa, M., Gilmore, J. H., Lin, W., \& Gerig, G. (2005). Automatic segmentation of MR images of the developing newborn brain. Medical Image Analysis, 9(5), 457-466. https://doi.org/10.1016/j.media.2005.05.007

Pujol, J., Deus, J., Losilla, J. M., \& Capdevila, A. (1999). Cerebral lateralization of language in normal left-handed people studied by functional MRI. Neurology, 52(5), 1038. https://doi.org/10.1212/wnl.52.5.1038

Rademacher, J., Morosan, P., Schormann, T., Schleicher, A., Werner, C., Freund, H. J., \& Zilles, K. (2001). Probabilistic mapping and volume measurement of human primary auditory cortex. Neuroimage, 13(4), 669-683.

https://doi.org/10.1006/nimg.2000.0714
Raschle, N. M., Lee, M., Buechler, R., Christodoulou, J. A., Chang, M., Vakil, M., ..., \& Gaab, N. (2009). Making MR imaging child's play - Pediatric neuroimaging protocol, guidelines and procedure. Journal of Visualized Experiments, (29). https://doi.org/10.3791/1309

Rosenberg-Lee, M., Barth, M., \& Menon, V. (2011). What difference does a year of schooling make?: Maturation of brain response and connectivity between $2^{\text {nd }}$ and $3^{\text {rd }}$ grades during arithmetic problem solving. NeuroImage, 57(3), 796-808. https://doi.org/10.1016/j.neuroimage.2011.05.013

Rossi, S., Lanoë, C., Poirel, N., Pineau, A., Houdé, O., \& Lubin, A. (2015). When I met my brain: Participating in a neuroimaging study influences children's naïve mindbrain conceptions. Trends in Neuroscience and Education, 4(4), 92-97. https://doi.org/10.1016/j.tine.2015.07.001

Sanchez, C. E., Richards, J. E., \& Almli, C. R. (2012). Neurodevelopmental MRI brain templates for children from 2 weeks to 4 years of age. Developmental Psychobiology, 54(1), 77-91. https://doi.org/10.1002/dev.20579

Shaywitz, B. A., Shaywitz, S. E., Pugh, K. R., Mencl, W. E., Fulbright, R. K., Skudlarski, P., ..., \& Gore, J. C. (2002). Disruption of posterior brain systems for reading in children with developmental dyslexia. Biological Psychiatry, 52(2), 101-110. https://doi.org/10.1016/s0006$\underline{3223(02) 01365-3}$

Shonkoff, J. P., \& Levitt, P. (2010). Neuroscience and the future of early childhood policy: Moving from why to what and how. Neuron, 67(5), 689-691. https://doi.org/10.1016/j.neuron.2010.08.032

Sigman, M., Peña, M., Goldin, A. P., \& Ribeiro, S. (2014). Neuroscience and education: Prime time to build the bridge. Nature Neuroscience, 17(4), 497-502. https://doi.org/10.1038/nn.3672

Supekar, K., \& Menon, V. (2012). Developmental maturation of dynamic causal control signals in higher-order cognition: A neurocognitive network model. PLoS Computational Biology, 8(2), e1002374. https://doi.org/10.1371/journal.pcbi.1002374

The Royal Society. (2011). Neuroscience: Implications for education and lifelong learning. London, UK: The Royal Society.

Thomas, K. M., \& Casey, B. J. (2000). Functional MRI in pediatrics. In C. Moonen \& P. A. Bandettini (Eds), Functional MRI (pp. 513-523). Berlin Heidelberg New York: Springer-Verlag.

Uylings, H. B. M., Rajkowska, G., Sanz-Arigita, E., Amunts, K., \& Zilles, K. (2005). Consequences of large interindividual variability for human brain atlases: Converging macroscopical imaging and microscopical neuroanatomy. Anatomy and Embryology, 210(56), 423-431. https://doi.org/10.1007/s00429-005-0042-4 
van der Kouwe, A. J. W., Benner, T., Salat, D. H., \& Fischl, B. (2008) Brain morphometry with multiecho MPRAGE. NeuroImage, 40(2), 559-569. https://doi.org/10.1016/j.neuroimage.2007.12.025

Vogel, S. E., Matejko, A., A., \& Ansari, D. (2016). Imaging the developing human brain using functional and structural magnetic resonance imaging: Methodological and practical guidelines. In J. Prior \& J. V. Herwegen (Eds.), Practical research with children (pp. 72-95). New York, NY: Routledge.

Wade, M., Fox, N. A., Zeanah, C. H., \& Nelson, C. A. (2019). Long-term effects of institutional rearing, foster care, and brain activity on memory and executive functioning. Proceedings of the National Academy of Sciences, 116(5), 1808-1813. https://doi.org/10.1073/pnas.1809145116
Wilke, M., Holland, S. K., Altaye, M., \& Gaser, C. (2008). Template-O-Matic: A toolbox for creating customized pediatric templates. NeuroImage, 41(3), 903-913. https://doi.org/10.1016/j.neuroimage.2008.02.056

Wilke, M., Holland, S. K., Myseros, J. S., Schmithorst, V. J., \& Ball, W. S. (2003). Functional magnetic resonance imaging in pediatrics. Neuropediatrics, 34(5), 225-233. https://doi.org/10.1055/s-2003-43260

Wilke, M., Schmithorst, V. J., \& Holland, S. K. (2002). Assessment of spatial normalization of whole-brain magnetic resonance images in children. Human Brain Mapping, 17(1), 48-60. https://doi.org/10.1002/hbm.10053 